\title{
Spontaneous abortion and work with visual display units
}

\author{
Eve Roman, Valerie Beral, Margo Pelerin, Carol Hermon
}

\begin{abstract}
Objective-To determine whether women who work with visual display units are at increased risk of spontaneous abortion.

Design-Case-control study.

Setting-Women were recruited during the three years 1987-9 from the Royal Berkshire Hospital in Reading, and from a large group practice situated within the hospital's catchment area.

Subjects-Cases were 150 nulliparous working women with a clinically diagnosed spontaneous abortion and controls were 297 nulliparous working women attending for antenatal care.

Main outcome measures-Cases and controls were contacted and personally interviewed using the same structured questionnaire. Exposure to visual display units (VDUs) at work was assessed from information supplied at interview.

Results-No evidence of an increased risk of spontaneous abortion was found in women who reported that they used a VDU at work compared with women who reported that they did not (odds ratio (OR) $=0.9,95 \%$ confidence interval $(95 \% \mathrm{CI})=0.6-1.4)$; and no relation with the amount of time spent actively using a VDU was evident $(\mathrm{OR}=0.9,95 \% \mathrm{CI}=0.5-1.6$ for women who worked with a VDU for 21 hours or more each week). No effect of passive exposure to VDUs at work was found $(O R=0.9,95 \% C I=0.6-1.6$ for women who reported working less than 10 feet away from a VDU that was usually switched on). These findings were not explained by maternal age, marital state, housing tenure, partner's social
\end{abstract}

Imperial Cancer Research Fund, Cancer Epidemiology Unit, Gibson Building, Radcliffe Infirmary, Oxford OX2 6HE

E Roman, V Beral, C Hermon

Communicable Disease Surveillance Centre, Public Health Laboratory Service, 61 Colindale Avenue, Colindale, London NW9 5EQ

M Pelerin class, educational level, smoking, alcohol consumption, or number of previous spontaneous abortions.

Conclusion-Given the findings and their consistency with the results from other recent studies it is concluded that pregnant women who work with VDUs are not at increased risk of clinically diagnosed spontaneous abortion. For the many women who use VDUs in their jobs, this finding provides reassurance.

The possible harmful effects of visual display units (VDUs) on reproductive outcome continues to be a topic of debate. ${ }^{1-13}$ Allegations that maternal work with VDUs was responsible for clusters of birth defects and fetal deaths were first made in the popular press in Canada and the United States in the mid1970s. ${ }^{1-3}$ The commonest adverse outcome referred to in the early reports was spontaneous abortion and in their wake a number of studies were set up to investigate the validity of these claims. The findings of many studies have been difficult to interpret because of problems with their design. Particular concern has been expressed about the validity of using self reported information to assess spontaneous abortion, and about the inadequate control of nonoccupational factors. ${ }^{3-12}$

The case-control study described here was specifically designed to investigate the alleged increased incidence of spontaneous abortion in women exposed to VDUs at work. To avoid the problems associated with biased reports of past pregnancies, we studied current clinically confirmed pregnancies. Furthermore, to minimise the effects of confounding by parity and other related factors, our investigations were restricted to nulliparous women. Women expecting their first child are more likely to work outside the home than women expecting their second or subsequent child and the type of work they do when they first become pregnant is unlikely to be influenced by their reproductive history. ${ }^{14}$

\section{Subjects and methods}

Cases were nulliparous women with a clinically confirmed spontaneous abortion and controls were nulliparous pregnant women attending for antenatal 
Table 1 Response and gestational ages of nulliparous women with a clinically confirmed spontaneous abortion and attending for antenatal care by source of ascertainment, eligibility, and employment

\begin{tabular}{|c|c|c|c|c|}
\hline & \multicolumn{2}{|c|}{ Clinically confirmed spontaneous abortion } & \multicolumn{2}{|c|}{ Attending for antenatal care } \\
\hline & GP notification & Hospital admission & GP notification & Hospital visit \\
\hline $\begin{array}{l}\text { Number of women: } \\
\text { Identified } \\
\text { Interviewed } \\
\text { Employed at interview } \dagger\end{array}$ & $\begin{array}{l}20 \\
20 \\
20\end{array}$ & $\begin{array}{l}143 \\
140 \\
130\end{array}$ & $\begin{array}{l}153 \\
152 \\
145\end{array}$ & $\begin{array}{l}190^{\star} \\
162 \\
152\end{array}$ \\
\hline $\begin{array}{l}\text { Gestational age of pregnan } \\
\text { menstrual period) of emplc } \\
\text { Mean (SD) } \\
\text { Range }\end{array}$ & $\begin{array}{c}10 \cdot 3(2 \cdot 9) \\
7-17\end{array}$ & $\begin{array}{c}10 \cdot 8(2 \cdot 6) \ddagger \\
4-18\end{array}$ & $\begin{array}{c}12 \cdot 9(3 \cdot 3) \\
6-21\end{array}$ & $\begin{array}{l}15 \cdot 6(2 \cdot 9) \S \\
7-25\end{array}$ \\
\hline
\end{tabular}

^Estimated from hospital records.

tEmployed in this job for at least three months.

tBased on 129 women.

$\S$ Based on 149 women.

care. Cases and controls were recruited during the years 1987 to 1989 from the Royal Berkshire Hospital in Reading, and from a large group practice situated within the hospital's catchment area.

The response of women asked to participate in the study was good (table 1). All 20 women with a clinically diagnosed spontaneous abortion identified through their general practitioner were recruited. Of the 143 nulliparous women admitted to hospital with a spontaneous abortion only three were not interviewed, and two of these could not be traced. All but one of the 153 antenatal patients identified through their general practitioner agreed to be interviewed, and $162(85 \%)$ of the estimated 190 nulliparous women identified at the time of their first visit from the appointment lists of one of four of the hospital's antenatal clinics were interviewed.

All cases and controls were contacted and personally interviewed by one of us (MP) using the same structured questionnaire. Women admitted to hospital with a spontaneous abortion, and those notified to us by their general practitioner were contacted and interviewed usually at home. Pregnant women attending for their first antenatal appointment were interviewed during their visit to hospital.

Ten $(7 \%)$ women admitted to hospital with a spontaneous abortion reported that they had been unemployed or had changed their job in the three months before their miscarriage (table 1). Seven $(5 \%)$ women attending their general practitioner for confirmation of pregnancy, and $10(6 \%)$ women attending for their first hospital antenatal visit were either unemployed or had changed their job in the three months before the interview. These 27 women have been excluded from further analyses.

At the time of their spontaneous abortion, employed women admitted to hospital and employed women diagnosed by their general practitioner were, on average, 10.3 weeks and 10.8 weeks pregnant respectively (table 1 ). These women were interviewed, on average, three weeks after their mis- carriage when, if their pregnancy had continued, they would have been nearly 14 weeks pregnant. At the time of interview, pregnant working women notified to us by their general practitioner and pregnant working women identified at the time of their first hospital visit were 12.9 weeks and 15.6 weeks pregnant respectively.

In the occupational analyses, the findings were similar for women identified through their general practitioner and women identified through the hospital. The data have, therefore, been combined to form two groups: those with a clinical spontaneous abortion and those attending for antenatal care.

Women who reported that they were employed at the time of interview, and who had been in the same job for three months or more, were asked to describe their job and working conditions. Women who reported using a VDU in their current job were asked how long they had been using it, what tasks they used it for, and how many hours, on average, they used it each week. The women were also asked about the location of the VDU that they used most of the time, and whether when the VDU was not being used by them it was usually switched on or switched off. To investigate further the effects of passive exposure, all women who reported the presence of VDUs in the room where they worked most of the time (regardless of whether or not those machines were ever used by them), were asked a further series of questions about the number and location of VDUs in their room, and whether these VDUs were usually switched on or switched off when they were not being actively used.

Other occupational questions about overtime, shiftwork, physical activity at work, physical comfort at work, and the acceptability of their general working environment were included. The women were also asked how satisfied they were with their present job, and whether they ever considered themselves under pressure at work. During the interview, information about other relevant factors including marital state, type of housing, education, partner's 
occupation, previous miscarriage, diet, smoking, and alcohol consumption was also sought.

The data were entered on to a microcomputer using the database management package Dbase III. ${ }^{15}$ Statistical analyses and data checking were carried out using SPSS $x^{16}$ and the unmatched option of the case-control analysis package EGRET. ${ }^{17}$

\section{Results}

Table 2 presents the characteristics of the 150 nulliparous working women with a clinically confirmed spontaneous abortion compared with those of the 297 nulliparous working women attending for antenatal care. Women who had had a spontaneous abortion were significantly older, were more likely to

Table 2 Characteristics of employed nulliparous women with a clinically confirmed spontaneous abortion compared with those of employed nulliparous women attending for antenatal care

\begin{tabular}{|c|c|c|}
\hline & $\begin{array}{l}\text { Clinically confirmed spontaneous abortion } \\
(n=150)\end{array}$ & $\begin{array}{l}\text { Attending for antenatal care } \\
(n=297)\end{array}$ \\
\hline & $\%(\mathrm{No})$ & $\%(\mathrm{No})$ \\
\hline \multicolumn{3}{|l|}{$\operatorname{Age}(y):$} \\
\hline$<25$ & $32(48)$ & $37(109)^{\star}$ \\
\hline $25-29$ & $37(56)$ & $44(130)$ \\
\hline$\geqslant 30$ & $31(46)$ & $20(58)$ \\
\hline \multicolumn{3}{|l|}{ Marital state: } \\
\hline Married/cohabiting & $93(139)$ & $91(269)$ \\
\hline \multicolumn{3}{|l|}{ Social class $\dagger$} \\
\hline I and II & $56(84)$ & $47(141)$ \\
\hline III & $36(54)$ & $43(127)$ \\
\hline IV and V & $6(9)$ & $8(24)$ \\
\hline Other & $2(3)$ & $2(5)$ \\
\hline \multicolumn{3}{|l|}{ Housing tenure: } \\
\hline Owner occupier & $90(135)$ & $82(244)^{\star}$ \\
\hline \multicolumn{3}{|l|}{ Education: } \\
\hline Further education & $57(86)$ & $45(134)^{\star}$ \\
\hline \multicolumn{3}{|c|}{ Smoking (cigarettes per day) $\ddagger$} \\
\hline None & $77(115)$ & $77(228)$ \\
\hline$\leqslant 14$ & $7(11)$ & $8(23)$ \\
\hline$\geqslant 15$ & $16(24)$ & $15(46)$ \\
\hline \multicolumn{3}{|c|}{ Alcohol (Drinks per week): } \\
\hline None & $28(42)$ & $26(78)$ \\
\hline $1-2$ & $25(38)$ & $21(63)$ \\
\hline $3-5$ & $27(41)$ & $29(85)$ \\
\hline$\geqslant 6$ & $19(29)$ & $24(71)$ \\
\hline \multicolumn{3}{|l|}{ Previous miscarriage } \\
\hline None & $87(131)$ & $92(274)$ \\
\hline 1 & $11(16)$ & $7(21)$ \\
\hline$\geqslant 2$ & $2(3)$ & $1(2)$ \\
\hline
\end{tabular}

*Significantly different from those admitted to hospital with a spontaneous abortion $(p<0.05)$.

tSocial class assigned on basis of partner's occupation.

† Smoking and drinking before pregnancy.

Table 3 Employment details of nulliparous women with a clinically confirmed spontaneous abortion compared with those attending for antenatal care

\begin{tabular}{|c|c|c|}
\hline & $\begin{array}{l}\text { Clinically confirmed spontaneous abortion } \\
(n=150)\end{array}$ & $\begin{array}{l}\text { Attending for antenatal care } \\
(n=297)\end{array}$ \\
\hline & $\%(\mathrm{No})$ & $\%(\mathrm{No})$ \\
\hline \multicolumn{3}{|l|}{ Type of occupation: } \\
\hline Non-manual & 89 (133) & $88(260)$ \\
\hline Manual & $11(17)$ & $12(37)$ \\
\hline \multicolumn{3}{|l|}{ Hours worked each week: } \\
\hline$\leqslant 35$ & $24(36)$ & $28(83)$ \\
\hline$\geqslant 36$ & $76(114)$ & $72(214)$ \\
\hline Shiftwork & $9(14)$ & $9(27)$ \\
\hline \multicolumn{3}{|l|}{ Equipment used at work: } \\
\hline VDUs & $55(82)$ & $57(168)$ \\
\hline Typewriter & $39(59)$ & $41(122)$ \\
\hline Telephone switchboard & $23(34)$ & $25(75)$ \\
\hline
\end{tabular}


own their own home, and to have a further educational qualification $(p<0.05)$. The differences in housing tenure and education were largely due to differences in age, and after adjustment for age they were no longer statistically significant. Women who had had a spontaneous abortion were also more likely to be married, to be of higher social class, and to have had one or more previous miscarriages than the control women, but these differences were not statistically significant and were again largely due to differences in age. The two groups of women were similar for reported cigarette and alcohol consumption before pregnancy. The employment details reported by the two groups of women were also similar (table 3). At the time of their pregnancy nearly $90 \%$ of both groups were in non-manual jobs. About three quarters of those interviewed worked for 36 hours or more each week, and over half reported that they used VDUs in their job.

Table 4 gives the unadjusted and adjusted odds ratios (ORs) associated with the use of VDUs. The
ORs in the first column are unadjusted. The ORs in the second column are adjusted for age, marital state, housing tenure, partner's social class, education, smoking, alcohol consumption, and number of previous spontaneous abortions. The pattern of VDU use in the two groups was similar with respect to overall use, and to the number of hours spent each week using the VDU. The findings were the same when the analysis was restricted to women who worked full time ( 36 hours or more each week). The data were also examined with respect to the tasks the VDU was used for, but again no differences between the groups were found.

Table 5 presents data on passive exposure to VDUs in women who worked full time. Women who did not use a VDU and did not work in a room containing a VDU were taken as the reference group for these analyses. The remaining women were divided into four passive exposure categories according to whether the closest VDU to them was usually switched on or switched off, and whether it was less

Table 4 Reported VDU use in employed nulliparous women with a clinically confirmed spontaneous abortion compared with that of nulliparous pregnant women attending for antenatal care according to the number of hours worked each week

\begin{tabular}{|c|c|c|c|c|}
\hline & \multirow{2}{*}{$\begin{array}{l}\text { Clinically confirmed } \\
\text { spontaneous abortion } \\
\% \quad(\text { No })\end{array}$} & \multirow{2}{*}{$\begin{array}{l}\text { Attending for } \\
\text { antenatal care } \\
\% \quad \text { (No) }\end{array}$} & \multicolumn{2}{|c|}{$O R(95 \% C I)$} \\
\hline & & & Unadjusted & Adjusted $^{\star}$ \\
\hline \multicolumn{5}{|c|}{ All employed women } \\
\hline $\begin{array}{l}\text { Non-VDU users } \\
\text { VDU users }\end{array}$ & $45(68)$ & $43(129)$ & Reference & Reference \\
\hline \multicolumn{4}{|l|}{ Hours worked each week using the VDU: } & \\
\hline$\leq 10$ & $27(40)$ & $26(77)$ & $1 \cdot 0(0 \cdot 6-1 \cdot 6)$ & $0.9(0.5-1.5)$ \\
\hline $11-20$ & $12(18)$ & $11(34)$ & $1.0(0.5-1.9)$ & $1.0(0.5-1.9)$ \\
\hline$\geqslant 21$ & $16(24)$ & $19(57)$ & $0.8(0.5-1.4)$ & $0.9(0 \cdot 5-1 \cdot 6)$ \\
\hline \multicolumn{5}{|c|}{ Women working 36 hours or more each week } \\
\hline Non-VDU users & $42(48)$ & $41(86)$ & Reference & Reference \\
\hline $\begin{array}{l}\text { VDU users } \\
\text { Hours worked each week using the VDU: }\end{array}$ & $58(66)$ & $59(125)$ & $0.9(0.6-1 \cdot 5)$ & $0.9(0.6-1 \cdot 5)$ \\
\hline \multicolumn{5}{|l|}{ Hours worked each week using the VDU: } \\
\hline $\begin{array}{l}\leqslant 10 \\
11-20\end{array}$ & $25(28)$ & $25(52)$ & $1 \cdot 0(0 \cdot 5-1 \cdot 7)$ & $\begin{array}{l}0.9(0.5-1 \cdot 6) \\
1 \cdot 0(0.5-2.1)\end{array}$ \\
\hline $\begin{array}{l}11-20 \\
\geqslant 21\end{array}$ & $16(18)$ & $15(31)$ & $1 \cdot 0(0 \cdot 5-2 \cdot 1)$ & $1 \cdot 0(0 \cdot 5-2 \cdot 1)$ \\
\hline$\geqslant 21$ & $18(20)$ & $20(42)$ & $0.9(0.5-1.6)$ & $1.0(0.5-1.9)$ \\
\hline
\end{tabular}

^Adjusted for age, marital state, housing tenure, social class (on basis of partner's occupation), education, smoking, alcohol, and number of previous spontaneous abortions.

Table 5 Passive exposure to VDUs in nulliparous women working 36 hours or more each week with a clinically confirmed spontaneous abortion compared with that of nulliparous women attending for antenatal care

\begin{tabular}{|c|c|c|c|c|}
\hline & \multirow{2}{*}{$\begin{array}{l}\text { Clinically confirmed } \\
\text { spontaneous abortion } \\
(n=114) \\
\% \quad(\text { No })\end{array}$} & \multirow{2}{*}{$\begin{array}{l}\text { Attending for } \\
\text { antenatal care } \\
(n=210) \dagger \\
\%(N o)\end{array}$} & \multicolumn{2}{|l|}{$O R(95 \% C I)$} \\
\hline & & & Unadjusted & Adjusted $^{\star}$ \\
\hline $\begin{array}{l}\text { Non-VDU users: } \\
\text { no passive exposure } \\
\text { VDU left on: } \ddagger\end{array}$ & $41(47)$ & $36(75)$ & Reference & Reference \\
\hline $\begin{array}{l}\leqslant 10 \text { feet away } \\
>10 \text { feet away }\end{array}$ & $\begin{array}{l}45(51) \\
3(3)\end{array}$ & $\begin{array}{r}44(93) \\
7(14)\end{array}$ & $\begin{array}{l}0.9(0.5-1.4) \\
0.3(0.1-1.3)\end{array}$ & $\begin{array}{l}0.9(0 \cdot 6-1 \cdot 6) \\
0.3(0 \cdot 1-1 \cdot 2)\end{array}$ \\
\hline $\begin{array}{l}\text { VDU turned off: } \\
\leqslant 10 \text { feet away } \\
>10 \text { feet away }\end{array}$ & $\begin{array}{l}4(5) \\
7(8)\end{array}$ & $\begin{array}{c}4(8) \\
10(20)\end{array}$ & $\begin{array}{l}1.0(0.3-3.2) \\
0.6(0.3-1.6)\end{array}$ & $\begin{array}{l}0.8(0 \cdot 2-2 \cdot 7) \\
0 \cdot 6(0 \cdot 2-1 \cdot 6)\end{array}$ \\
\hline
\end{tabular}

*Adjusted for age, marital state, housing tenure, social class (on basis of partner's occupation), education, smoking, alcohol, and number of previous spontaneous abortions.

tOne woman was omitted because of missing information.

\$omen using a VDU for five hours or more a day are included, regardless of whether the VDU was switched on or switched off when not in use. 
Table 6 Reported working conditions and environments of nulliparous women with a clinically confirmed spontaneous abortion compared with those attending for antenatal care

\begin{tabular}{|c|c|c|c|c|}
\hline & \multirow{2}{*}{$\begin{array}{l}\text { Clinically confirmed } \\
\text { spontaneous abortion } \\
(n=150) \\
\% \quad(\text { No }) \\
\end{array}$} & \multirow{2}{*}{$\begin{array}{l}\text { Attending for } \\
\text { antenatal care } \\
(n=297) \\
\% \quad(N o) \\
\end{array}$} & \multicolumn{2}{|l|}{$O R(95 \% C I)$} \\
\hline & & & Unadjusted & Adjusted $\dagger$ \\
\hline $\begin{array}{l}\text { Uncomfortable work } \\
\text { Head and neck } \\
\text { Hands and arms } \\
\text { Back } \\
\text { Legs and feet }\end{array}$ & $\begin{array}{l}10(15) \\
6(9) \\
37(56) \\
11(17)\end{array}$ & $\begin{array}{r}11(33) \\
4(12) \\
30(89) \\
14(41)\end{array}$ & $\begin{array}{l}0.9(0.5-1.7) \\
1.5(0.6-3.7) \\
1.4(0.9-2.1) \\
0.8(0.4-1.5)\end{array}$ & $\begin{array}{l}1 \cdot 1(0 \cdot 5-2 \cdot 1) \\
1 \cdot 7(0 \cdot 7-4 \cdot 3) \\
1 \cdot 5(0 \cdot 9-2 \cdot 3) \\
0 \cdot 8(0 \cdot 4-1 \cdot 4)\end{array}$ \\
\hline $\begin{array}{l}\text { Unsatisfactory worki } \\
\text { respect to: } \\
\text { Light } \\
\text { Noise } \\
\text { Temperature } \\
\text { Static electricity } \\
\text { Pressurised at work } \\
\text { Dissatisfied with job }\end{array}$ & $\begin{array}{l}28(42) \\
21(32) \\
43(65) \\
22(33) \\
32(48) \\
11(16)\end{array}$ & $\begin{array}{l}24(72) \\
23(67) \\
47(141) \\
22(66) \\
29(85) \\
5(16)\end{array}$ & $\begin{array}{l}1.2(0.8-1.9) \\
0.9(0.6-1.5) \\
0.8(0.6-1.3) \\
1.0(0.6-1.6) \\
1.2(0.8-1.8) \\
2.1(1.0-4.3)\end{array}$ & $\begin{array}{l}1.2(0.8-1.9) \\
1.0(0.6-1.6) \\
0.9(0.6-1.3) \\
0.9(0.6-1.5) \\
1.1(0.7-1.7) \\
2.2(1.0-4.8)^{\star}\end{array}$ \\
\hline
\end{tabular}

*Significantly different from those admitted to hospital with a spontaneous abortion $(p<0.05)$.

†Adjusted for age, marital state, housing tenure, social class (on basis of partner's occupation), education, smoking, alcohol, and number of previous spontaneous abortions.

than or more than 10 feet away from where they usually worked. No differences between women with a clinically diagnosed spontaneous abortion and women attending for antenatal care are evident.

Table 6 compares the range of working conditions and the general working environments reported by the two groups of women. Those with a clinically diagnosed spontaneous abortion were more likely than those attending for antenatal care to report that their work posture was uncomfortable for their hands and arms $(\mathrm{OR}=1.8,95 \%$ confidence interval $(95 \%$ CI) $=0.7-4.4)$, and for their back (OR $=1.5,95 \%$ $\mathrm{CI}=0 \cdot 9-2 \cdot 2$ ), but these differences were not statistically significant at the $5 \%$ level. The reported working environments of the two groups of women for light, noise, temperature, and static electricity were similar. No differences as to whether or not the women considered themselves under pressure at work were reported, although more women with a clinically diagnosed spontaneous abortion said they were dissatisfied with their job (OR $=2 \cdot 2,95 \%$ $\mathrm{CI}=1 \cdot 0-4 \cdot 8)$.

\section{Discussion}

These results suggest that women who work with VDUs are not at increased risk of clinically diagnosed spontaneous abortion. No differences in the number of hours spent each week using the VDU or the tasks that the VDU was used for were found, and no association with passive exposure to VDUs at work was seen.

Just over half of the nulliparous working population investigated reported using a VDU in their job; and at this degree of exposure the study was sufficiently large to have had a $90 \%$ chance of detecting a doubling of risk at the $5 \%$ significance level, should one have existed. In fact, none of the
ORs calculated for active use of VDUs exceeded unity (table 4). To check the validity and reliability of responses given at interview, a sample of study members was contacted and reinterviewed by $\mathrm{Dr}$ Mackay of the Health and Safety Executive. No evidence of bias in reporting as a function of casecontrol state was found, and further details of the validation study, which will be the subject of a separate report, can be obtained from Dr Mackay. ${ }^{18}$

For the many women who use VDUs in their jobs the results presented here provide reassurance. Our findings are consistent with three recently published studies, one from Canada ${ }^{6}$ and two from America. ${ }^{12}{ }^{13}$ Our study was specially designed to minimise confounding by non-occupational factors. Only current pregnancies and current VDU exposures were considered. All of the women were nulliparous and all had clinically confirmed pregnancies. The lack of an association in this relatively homogeneous group of women offers further support for the view that the results of earlier poorly designed studies were erroneous. ${ }^{8-10}$

Most concern about the possible adverse reproductive effects of maternal exposure to VDUs at work has centred on recognised spontaneous abortion. Unrecognised pregnancy loss is difficult to diagnose and its clinical significance is unclear. ${ }^{19}$ That the association between recognised spontaneous abortion and exposure to VDUs at work has not been confirmed makes it unlikely, although not impossible, that losses very early in pregnancy could be related to parental exposure to VDUs.

Women with a clinically diagnosed spontaneous abortion were marginally more likely than their antenatal counterparts to report that their work posture was uncomfortable and that they were dissatisfied with their job (table 6). These findings are of borderline statistical significance and could be 
due to biased reporting. Others have failed to show an association between spontaneous abortion and work posture ${ }^{20}$ and the suggestion that stress may be related to adverse pregnancy outcome is not new. 3721

In conclusion, women who work with VDUs are not at increased risk of clinically recognised spontaneous abortion. Given the consistency of our findings with those from recent studies it is reasonable to conclude that further research in this area is unwarranted.

We thank the staff at the Royal Berkshire Hospital in Reading and the Brookside practice in Lower Earley whose generous cooperation made this study possible. We are particularly indebted to the many women who gave up their time to help us with this research, and to Dr Colin Mackay of the Health and Safety Executive for his advice and support throughout the study. Cherill Scott assisted in the early stages of the study and Sarah Jones typed the many drafts of the manuscript.

Eve Roman, Valerie Beral, and Margo Pelerin were based in the Medical Research Council's Epidemiological Monitoring Unit at the London School of Hygiene and Tropical Medicine during the data collection phase of the study, and the Health and Safety Executive sponsored much of the work.

1 Purdham J. Adverse pregnancy outcome amongst VDU operators - the cluster phenomenon. In: allegations of reproductive hazards from VDUs. Humane Technology, 1984:27-40.

2 Lee WR. Working with visual display units. $B M J 1985 ; 291$ : 989-91.

3 MacKay C. Visual display unit operation: possible reproductive effects. In: Allegations of reproductive hazards from VDUs. Humane Technology 1984:137-59.
4 Ericson A, Kallen B. An epidemiological study of work with video screens and pregnancy outcome: I. A registry study. $A m$ $J$ Ind Med 1986;9:447-57.

5 Ericson A, Kallen B. An epidemiological study of work with video screens and pregnancy outcome: II. A case-control study. Am J Ind Med 1986;9:459-75.

6 McDonald AD, McDonald JC, Armstrong B, Cherry N, Nolin $\mathrm{AD}$. Work with visual display units in pregnancy. $\mathrm{Br} J$ Ind Med 1988;45:509-15.

7 Blackwell R, Chang A. Video display terminals and pregnancy. A review. Br J Obstet Gynaecol 1988;95:446-53.

8 Goldhaber KM, Polen MR, Hiatt RA. The risk of miscarriage and birth defects among women who use visual display terminals during pregnancy. Am J Ind Med 1988;13:695-706.

9 Robinson $H$. The risk of miscarriage and birth defects among women who use visual display terminals during pregnancy. Am J Ind Med 1989;15:357-8.

10 Goldhaber MK, Polen RM, Hiatt RA. Authors' response. VDTs and miscarriage. Am J Ind Med 1989;15:359-60.

11 Bergquist U. Possible health effects of working with VDUs. Br J Ind Med 1989;46:217-21.

12 Bryant HE, Love EJ. Video display terminal use and spontaneous abortion. Int J Epidemiol 1989;18:132-8.

13 Schnorr TM, Crajewski BA, Hornung RW, et al. Video display terminals and the risk of spontaneous abortion. $N$ Engl J Med 1991;324:727-33.

14 Martin J, Ceridwen R. Women and employment. A lifetime perspective. London: HMSO, 1984. Report of the 1980 DE/OPCS Women and Employment Survey.

15 Dbase III + . Ashton Tate, 1985.

16 SPSS Incorporated. Statistical package for the social sciences$X$ : User's guide. New York: McGraw Hill, 1989.

17 Statistics and Epidemiology Research Corporation. EGRET Seattle: Statistics and Epidemiology Research Corporation, 1985.

18 Mackay C. Personal communication. Health and Safety Executive, Magdalen House, Trinity Road, Bootle, Merseyside L20 30Z.

19 Beral V, Doyle P, Tan SC, Mason BA, Campbell S. Outcome of pregnancies resulting from assisted conception. British Medical Bulletin 1990;46:735-68.

20 Goulet L, Gilles T. Association between spontaneous abortion and ergonomic factors. Scand J Work Environ Health 1986: $399-403$.

21 Newton RW. Psychosocial aspects of pregnancy: the scope for intervention. Journal of Reproductive and Infant Psychology 1988;6:23-39.

Accepted 4 November 1991 